\title{
Generation of residual stresses in rotary swaging process
}

\author{
Dhia Charni ${ }^{1, *}$, Svetlana Ishkina ${ }^{2,3}$, Jérémy Epp $^{1,4}$, Marius Herrmann ${ }^{2,3}$, Christian Schenck ${ }^{2,3,4}$, Hans-Werner \\ Zoch $^{1,3,4}$, and Bernd Kuhfuss ${ }^{2,3,4}$ \\ ${ }^{1}$ Leibniz Institute for Materials Engineering - IWT, Badgasteiner Str. 3, 28359 Bremen, Germany \\ ${ }^{2}$ Bremen Institute for Mechanical Engineering - bime, Badgasteiner Str. 1, 28359 Bremen, Germany \\ ${ }^{3}$ University of Bremen \\ ${ }^{4}$ MAPEX Center for Materials and Processing
}

\begin{abstract}
Infeed rotary swaging is an established incremental cold forming production technique for axisymmetric workpieces. Among others, work hardening as well as near net shape forming are advantages of this production technique. Due to the incremental open die forging process, the rotary swaging induces a complex material flow history which is dependent on the process control. This material flow history influences the material modifications such as work hardening as well as residual stresses. In this study, the properties of steel tubes were investigated after rotary swaging using varying parameters by experimental and simulation analysis. In particular, the influence of lubrication with different feeding velocities was analysed. The workpiece quality, the hardness and the residual stresses were characterized in detail. After rotary swaging, an influence of the process parameters on the geometrical and surface quality could be observed. The workpieces showed significant work hardening which was higher at the surface and process dependent, while below $100 \mu \mathrm{m}$, this increased hardness was observed over the complete wall thickness independently of the process parameters. The residual stress state was highly fluctuating at the surface and was in tensile for all conditions. The results showed that the process parameters influenced the properties near the surface, while a few hundred micrometers below the surface, the workpiece properties seemed to be driven only by the total deformation.
\end{abstract}

Keywords. Cold forming, Microstructure, Residual stress.

\section{Introduction}

Infeed rotary swaging is a non-cutting chipless cold forming process and has an important field of application in the automotive industry. Commonly it is used to produce axisymmetric components, such as axes, steering spindles and gear shafts [1]. Thereby the cross section is incrementally reduced by repeated radial strokes of oscillating dies [2]. During the process, the swaging unit is rotating and the base jaws are passing the cylinder rollers which induces simultaneously radial short strokes of the dies, as shown in Figure 1. The forming process has several positive effects on the produced workpieces like undisturbed fibre flow as well as improved material properties like increased tensile strength and hardness due to work hardening [1]. Furthermore, especially for the production of hollow parts, an adjustable wall thickness production is possible to yield an optimal use of material resources for lightweight applications [3].

Due to the incremental open die forging process, rotary swaging takes place with a complex material flow which is dependent on the process control. This can be shown by the neutral plane shape and position which in general cases is located in the forging zone [4]. The neutral plane is defined as the plane in the workpiece in which the material is only deformed radially whereas alongside the neutral plane, the material is deformed radially and axially and flows away from the neutral plane. Lahoti and Altan [5] studied the influence of process parameters on the location of the neutral plane and concluded amongst others that the neutral plane shifted towards the preform (undeformed workpiece part) when the friction increased or when back push or front pull was applied. Consequently, more material flowed in the forward direction $[4,5]$. In another work, Wu et al [6] analysed the influence of several process parameters on the neutral plane that appeared to be not a planar cross section. Moumi found out that even its shape and its position changed during one single stroke [4].

This non-steady material flow has also been investigated by Liu. He showed that the material flow was fastest at the beginning of the stroke and then started to slow down to the end of this stroke [7]. This non steady material flow influenced the complex material modification such as work hardening as well as residual stresses [8].

Due to the use of components produced by rotary swaging under static and dynamic loads it was necessary to investigate the mechanisms of residual stress generation in order to be able to predict and control the

\footnotetext{
*Corresponding author: charni@iwt-bremen.de
} 
mechanical properties [9]. Ameli and Movahhedy investigated the residual stress distribution after rotary swaging process and found that these were significantly influenced by the incremental degree of the resulted deformation. It was found for tubular components that on the outer surface mainly tensile and on the inner surface mainly compressive residual stresses were present [10].

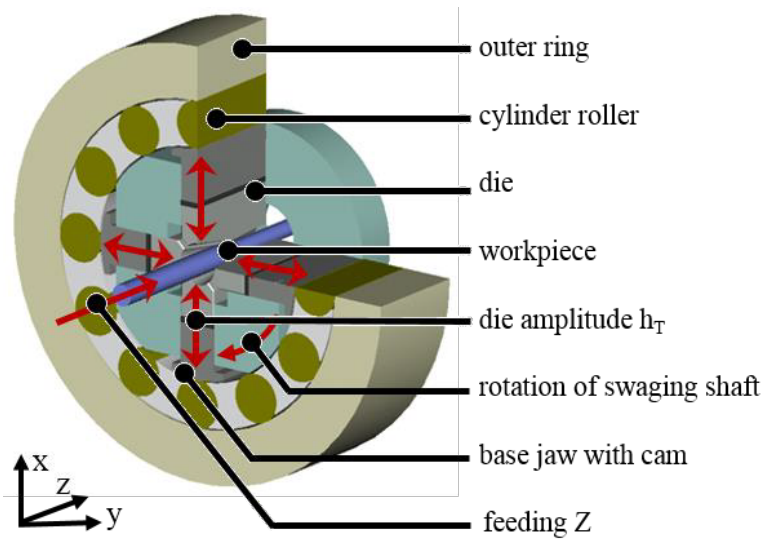

Fig. 1. Schematic operation of rotary swaging machine.

Since the final product shape can be achieved by different material flow histories, rotary swaging is a particularly suitable forming process to generate various residual stress and work hardening distributions. To achieve controlled material modifications, it is necessary to understand the interdependency between the material flow, which is controlled by the process parameters and the resulting material modifications - in particular the residual stress state. As a consequence of the induced work hardening and residual stress distribution, it is expected that various static and dynamic mechanical properties can be achieved without modification of the component geometry itself but just by tuning the rotary swaging process parameters.

For this qualitative study, infeed rotary swaging with different process conditions was performed. The local work hardening and microstructural evolution was characterized. Additionally, residual stress distributions generated by this process were investigated. The residual stresses were measured and broad variations were observed. Based on these results, a first assessment of the influence of the rotary swaging process control on the resulting material modifications could be achieved.

\section{Experimental setup}

\subsection{Rotary swaging}

The material used for this study is cold drawn E235JR steel tubes of $1_{0}=300 \mathrm{~mm}$ initial length, $\mathrm{d}_{0}=20 \mathrm{~mm}$ initial diameter and $\mathrm{s}_{0}=2 \mathrm{~mm}$ initial wall thickness. The tubes exhibited a zinc phosphate coating of about $1 \mu \mathrm{m}$ thickness as usually applied for corrosion protection or friction reduction to decrease die wear. Single pass rotary swaging experiments were carried out on these tubes, using a rotating shaft at $300 \mathrm{rpm}$, reducing the diameter down to $d_{1}=15 \mathrm{~mm}$. The stroke following angle that is defined as the angle of rotation around the $\mathrm{z}$-axis between two successive strokes was about $51^{\circ}$. The used dies were conventional powder-metallurgical ASP $\AA 2023$ made of 1.2379 steel with a die angle $\alpha=10^{\circ}$ and a calibration length $1_{\text {cal }}=20 \mathrm{~mm}$. The reduction zone of these dies featured a spray-coated tungsten carbide layer (see Figure 2) which increased the effective friction between the dies and the workpiece to reduce the axial reaction force of the preform [2]. For all experiments the stroke height of the dies was set to $\mathrm{h}_{\mathrm{T}}=1 \mathrm{~mm}$ and the stroke frequency to $f_{s t}=37.5 \mathrm{~Hz}$. The tubes were fed with a linear direct drive into the swaging unit with four different feed velocities $\left(v_{\mathrm{f}}=500 \mathrm{~mm} / \mathrm{min}, 1000 \mathrm{~mm} / \mathrm{min}\right.$, $1500 \mathrm{~mm} / \mathrm{min}$ and $2000 \mathrm{~mm} / \mathrm{min}$ ) and two different lubrication conditions (with and without lubrication), see Table 1.

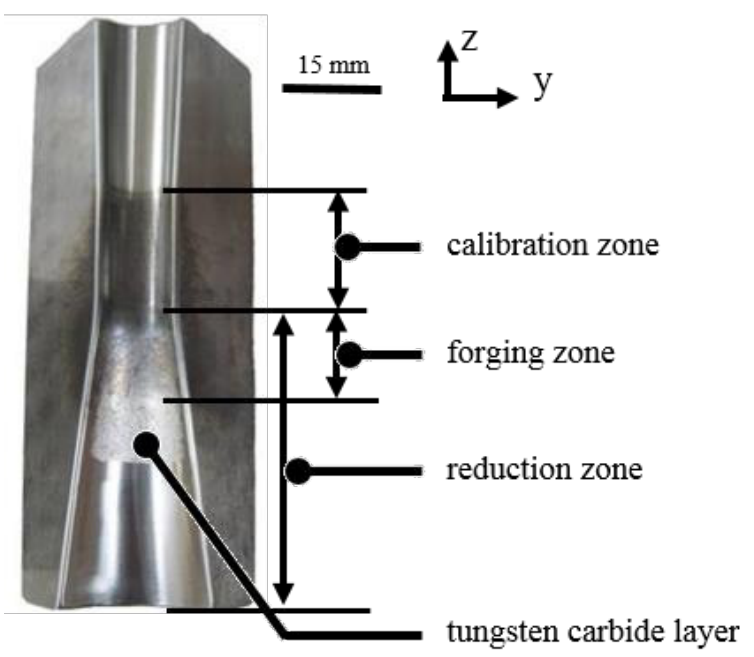

Fig. 2. Typical swaging die (one out of four).

Table 1. Design of experiments.

\begin{tabular}{|c|c|c|c|}
\hline Sample & $\begin{array}{l}\text { Lubrication } \\
\text { condition }\end{array}$ & $\begin{array}{c}\text { Feed } \\
\text { velocity } \\
(\mathrm{mm} / \mathrm{min})\end{array}$ & $\begin{array}{c}\text { Feed per } \\
\text { stroke } \\
\text { (mm/stroke) }\end{array}$ \\
\hline Init & \multicolumn{3}{|c|}{ Initial condition before rotary swaging } \\
\hline L500 & \multirow{4}{*}{ With lubricant } & 500 & 0.22 \\
\hline L1000 & & 1000 & 0.44 \\
\hline L1500 & & 1500 & 0.66 \\
\hline L2000 & & 2000 & 0.88 \\
\hline D500 & \multirow{4}{*}{$\begin{array}{l}\text { No lubricant } \\
\text { (dry) }\end{array}$} & 500 & 0.22 \\
\hline D1000 & & 1000 & 0.44 \\
\hline D1500 & & 1500 & 0.66 \\
\hline D2000 & & 2000 & 0.88 \\
\hline
\end{tabular}


From the stroke frequency and the feed velocity, a feed per stroke $v_{s t}$ can be deduced. Thus the lowest $\mathrm{v}_{\mathrm{f}}=500 \mathrm{~mm} / \mathrm{min}$ matches $\mathrm{v}_{\mathrm{st}}=0.22 \mathrm{~mm} /$ stroke and the highest $\mathrm{v}_{\mathrm{f}}=2000 \mathrm{~mm} / \mathrm{min}$ matches $\mathrm{v}_{\mathrm{st}}=0.88 \mathrm{~mm} /$ stroke. The lubricant used was a mineral oil Condocut KNR 22. Before each dry rotary swaging the dies and workpieces were cleaned thoroughly using ethanol. In addition, the samples were mounted in a clamping device at the swaging machine. They were clamped with a moderate tension force allowing the samples to rotate to minimize the torsion of the tubes that can be induced by the rotating dies upon stroke contact.

\subsection{Residual stress measurement}

The residual stresses were measured on selected samples (Init, L500, L2000, D500 and D2000) by X-Ray diffraction (XRD) using a GE inspection technologies diffractometer Type ETA 3003 with vanadium filtered $\mathrm{Cr}-\mathrm{K} \alpha$ radiation. The $\{211\}$ diffraction peak of $\alpha$-iron was evaluated using the conventional $\sin ^{2} \psi$-method [12]. Axial and tangential residual stresses were evaluated along a path of $20 \mathrm{~mm}$ on the outer surface of the tubes with a step size of $1 \mathrm{~mm}$ starting at an arbitrary position (Figure 3). The beam diameter was $1 \mathrm{~mm}$. The full width at half maximum (FWHM) of the diffraction peaks was also evaluated in order to obtain additional information on the microstructure and the microstresses. In cold forming processes of non-hardened steel, the FWHM correlates well with the hardness and allows a qualitative evaluation of its distribution [13]. Residual stress and FWHM depth profiles were also measured at one position on each sample. For this, the material removal was done by electrolytic etching using a solution of $\mathrm{H}_{3} \mathrm{PO}_{4}$ and $\mathrm{H}_{2} \mathrm{SO}_{4}$.

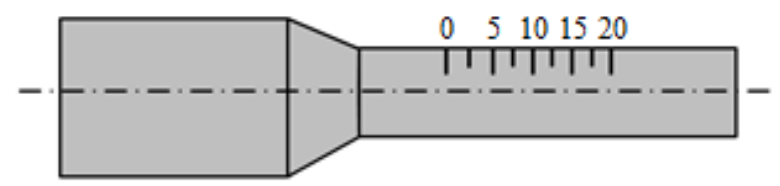

Fig. 3. Sketch of a swaged sample showing the positions of surface residual stress measurements.

\subsection{Metallographic examination and hardness measurement}

The microstructure of the samples was investigated after standard metallographic preparation. After cutting transverse sections from the different tubes, these were embedded, ground and polished. An optical microscope was used to examine the effect of the process on the microstructure at the outer wall surface after etching using a $3 \%-\mathrm{HNO}_{3}$ alcoholic solution. Additionally, the hardness was measured using Vickers indentations with a load of $1 \mathrm{~N}$ for depth profiles analysis on the cross section and $5 \mathrm{~N}$ for measurements directly at the outer surface. All results were calculated from the average of 3 measurements.

\section{Results and discussion}

\subsection{Workpiece geometry and quality}

The workpiece geometry was analysed after the rotary swaging experiments. The final diameter of all formed samples exhibited almost the same value (deviation less than $100 \mu \mathrm{m}$ ). Hence, differences were recognized in the final length of the tubes. For higher feed velocity the length difference was increased, also for forming without lubricant ("dry") longer workpieces were achieved, see Figure 4. Furthermore, the wall thickness is smaller than for the workpieces formed by lower feed velocity or with lower friction conditions during forming., which was seen in cross sections. This means that for these conditions, the material flow in axial direction is higher.

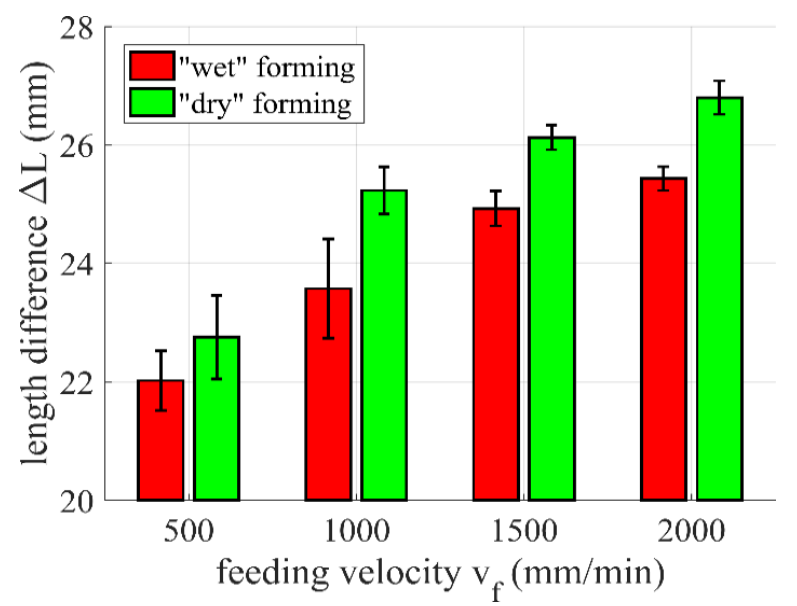

Fig. 4. Length different $\Delta \mathrm{L}$ with standard deviation for wet and dry forming with different feed velocities.

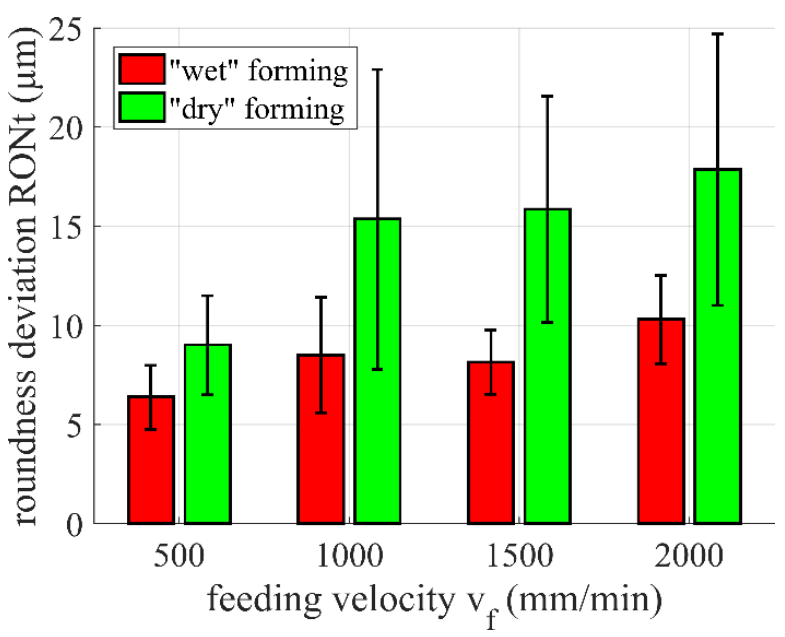

Fig. 5. Roundness deviation RONt with standard deviation for wet and dry forming with different feed velocities.

Additionally, the roundness deviation was measured, see Figure 5. It could be observed that with higher feed velocity the roundness deviation increased. Furthermore, dry forming compared to forming with lubricant led to higher roundness deviation as well as higher scatter. 
To examine the workpiece quality surface roughness measurements were carried out. For the forming with different feeding velocities it was recognized, that with increasing $\mathrm{v}_{\mathrm{f}}$ also the surface roughness Sa increased, see Figure 6. Due to the faster infeed of the workpiece the surface was deformed by less strokes and the deformation per stroke was higher. Thus a higher surface roughness $\mathrm{Sa}$ could be explained. This was also observed for dry forming. The higher roundness deviation and the surface roughness as well as the higher standard deviation of these properties during dry forming could be explained by the higher amount of the produced abraded particles which adhere on the surface of the workpiece and the dies due to the absent flushing of the forging zone by the lubricant [14].

The different number of strokes that formed the workpiece led to different surface developments. This can be observed, as illustrated in Figure 7, showing the surfaces of wet and dry formed workpieces with $\mathrm{V}_{\mathrm{f}}=500 \mathrm{~mm} / \mathrm{min} \quad$ (L500 and D500) and $\mathrm{V}_{\mathrm{f}}=2000 \mathrm{~mm} / \mathrm{min}$ (L2000 and D2000). The surface after forming with lubricant using the lowest feed velocity showed no obvious surface pattern, see Figure 7 a). For this forming with lubricant and the lowest feeding velocity, which represents the lowest effective friction condition, the zinc phosphate coating on the workpiece can no longer be recognized on the L500 samples, see blank surface in Figure 7 a). This shows that the effective friction was low and allowed the dies to slide on the surface of the tube during contact. For the lubricated forming with the highest feeding velocity a fine texture and still some deposits of the workpiece coating (dark spots) can be recognized due to less strokes on the surface, see Figure 7.b).

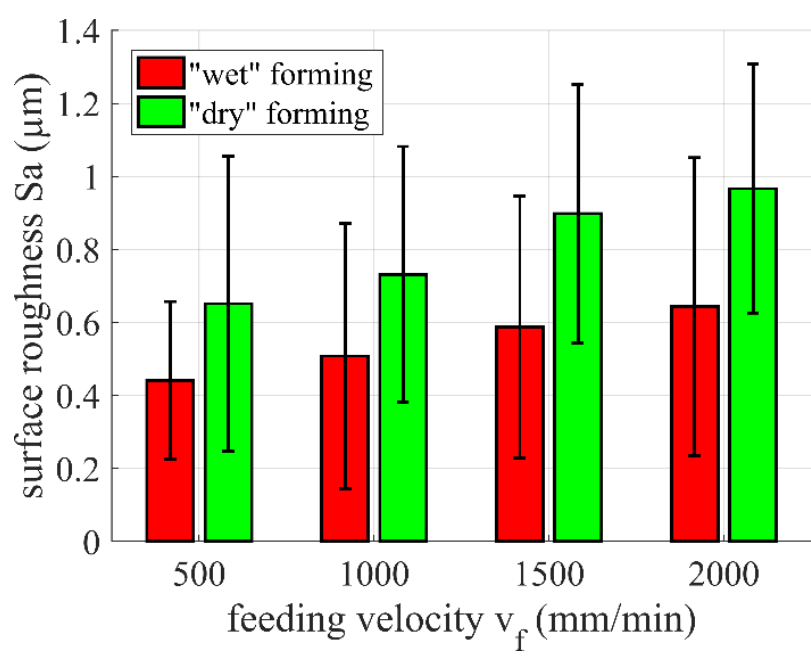

Fig. 6. Surface roughness Sa with standard deviation for wet and dry forming with different feed velocities.

However, dry forming produces a texture at the surface leading to pronounced helical patterns, see Figure $7 \mathrm{~d}$ ). This can be explained by the rotation of the dies around the workpiece between the strokes. Due to the absent lubricant and to the high feed velocity, the effective friction is very high. Furthermore, dry processing highly increased the process forces and the contact pressures [15]. Therefore, the adhesion was increased, preventing the dies from sliding on the tube which led to a slight torsion of the tube while the dies were closed. Thus, the helical texture was more pronounced and less removing of the workpiece coating was recognized.

Moreover, it was noticed that during the dry rotary swaging with high velocities, the D2000 samples were rotating much more than the D500 samples, while the lubricated samples were almost not rotating during the process.

a)

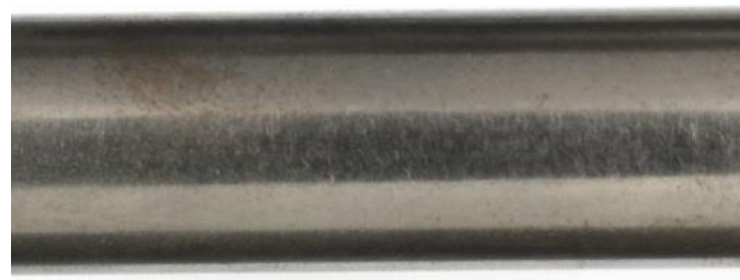

b)

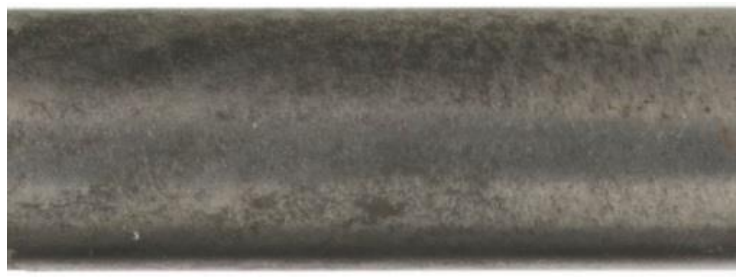

c)

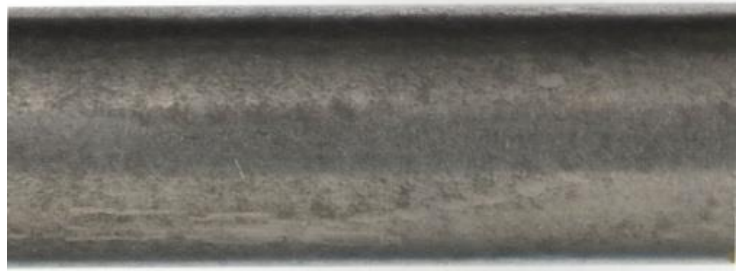

d)

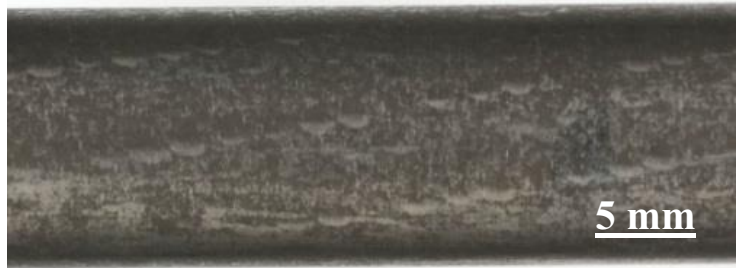

Fig. 7. Photos of the tube surfaces; a) L500, b) D500, c) L2000, d) D2000.

The observed surface patterns can also be identified on the roundness profiles of L500 and D2000 samples as the samples always exhibit an octagon-like shape. On the roundness profile of the lubricated formed tube around every $45^{\circ}$ an edge on the surface of about $3 \mu \mathrm{m}$ can be seen, Figure 8 a). This shape is more remarkably noticed on the workpiece processed with high effective friction with edges on the surface of about $6 \mu \mathrm{m}$, see Figure $8 \mathrm{~b}$ ). This supports the theory of the sliding of the dies on the surface of the workpiece occurring during low effective friction rotary swaging, so that the sliding on the octagon shape is profiling round edges. 


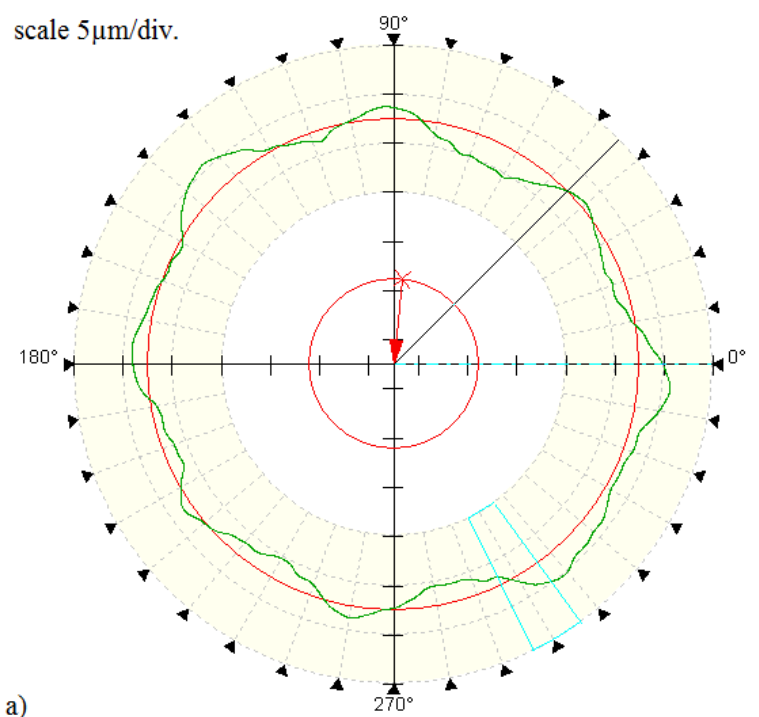

a)

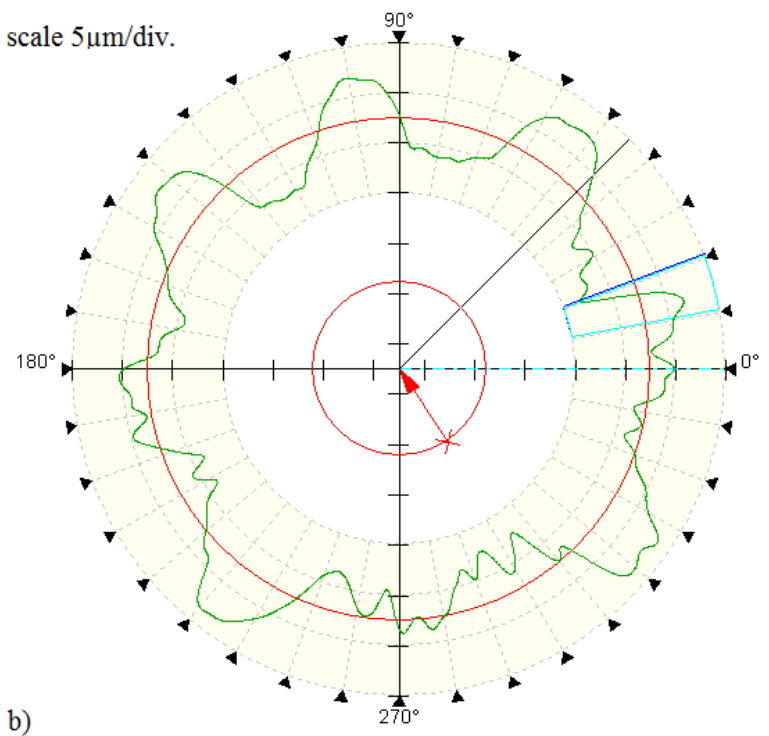

Fig. 8. Roundness profile: a) L500, b) D2000

\subsection{Simulated material flow}

The simulation enabled the investigation of the material flow in axial direction (forward and reverse) as well as in radial direction. The velocity magnitude and direction of the workpiece nodes during one stroke of the dies in rotary swaging process is shown in Figure 9, with feed of the samples in positive z-direction. It represents the moment of tools closing at $0.74 \mathrm{~ms}$ after the first contact of the workpiece with tools and $0.71 \mathrm{~ms}$ before the tools totally closed. The arrows show the direction and the magnitude is presented by the length of the arrows as well as the colour of the workpiece. The top section, see Figure 9 a), is illustrating the lower friction between the workpiece and the die while Figure $9 \mathrm{~b}$ ) represents the high friction for the friction pair "coated E235JR and 1.2379 steel". It can be observed, that the higher the friction coefficient is, the higher become the velocity of the nodes in the feeding direction (z-direction, forward), see Figure 9. It means that the higher the friction is, the more material flows forwards and less backwards. For lower friction coefficient, see Figure 9 the material tends to flow backwards and thus, a back-flow of the material takes place.

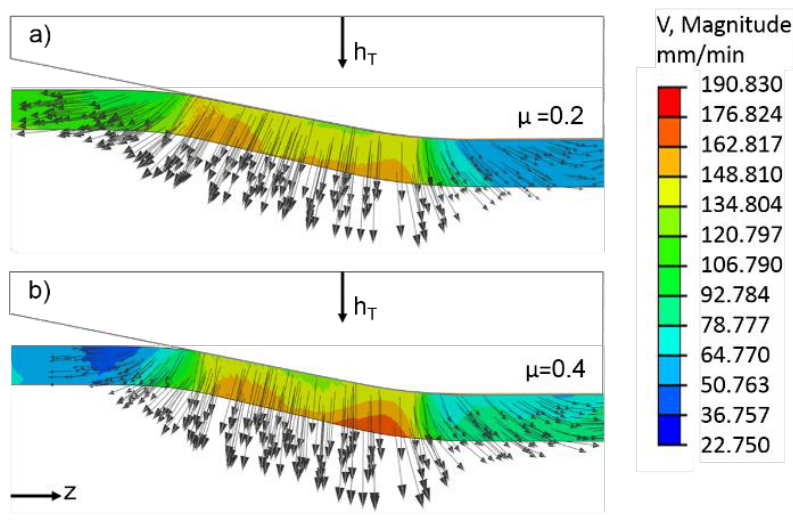

Fig. 9. Material velocity distribution of tubes during rotary swaging process at $\mathrm{vf}=2000 \mathrm{~mm} / \mathrm{min}$ for two different friction coefficients $\mu=0.2$ and $\mu=0.4$.

\subsection{Microstructure and hardness}

The surface near microstructure of the different conditions can be seen at high magnification in Figure 10. On the lubricated samples L500 and L2000, a layer of axially deformed grains was formed within the first 30$50 \mu \mathrm{m}$. This could be explained by the sliding of the dies on the workpiece and thus the additional deformation near the surface. On the other hand, the dry processed samples D500 and D2000 showed only slightly deformed grains near the surface. Additionally, the micrographs show that for higher feed velocities, the microstructure tended to be less axially deformed near the surface than for lower feed rate.

The effect of the rotary swaging on the Vickers hardness depth profile is shown in Figure 11. In initial conditions, a non-homogeneous hardness distribution was present through the thickness with hardness values close to $150 \mathrm{HV} 0.1$ and a decrease to one minimum of 119 HV0.1 at half the thickness. This was due to the prior cold drawing process, leading to a gradient in hardness over the entire thickness, as already observed in [16]. After rotary swaging, the measured hardness distribution was strongly increased for all process conditions and reached more or less homogeneous hardness values around $195 \mathrm{HV} 0.1$. The hardness increase could be attributed to the work hardening due to the plastic deformation during the rotary swaging process. However, no clear effect of the process parameters on the hardness distribution could be identified from these results. These hardness depth profiles were completed by surface hardness measurements, see Figure 12. It can be seen that the hardness values were higher than in deeper layers at the cross section. Here again, no clear difference between the process conditions could be identified. Based on these results, it could be assumed that in this case, the work hardening effect of the process is independent of the investigated process parameters. 


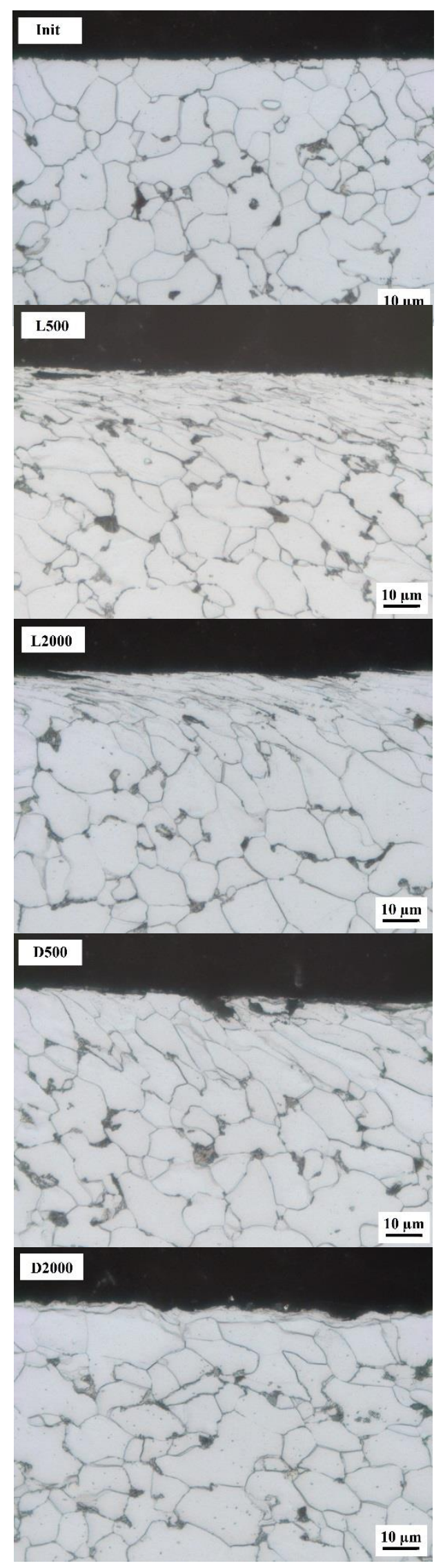

Fig. 10. Optical micrographs of longitudinal section of different samples.

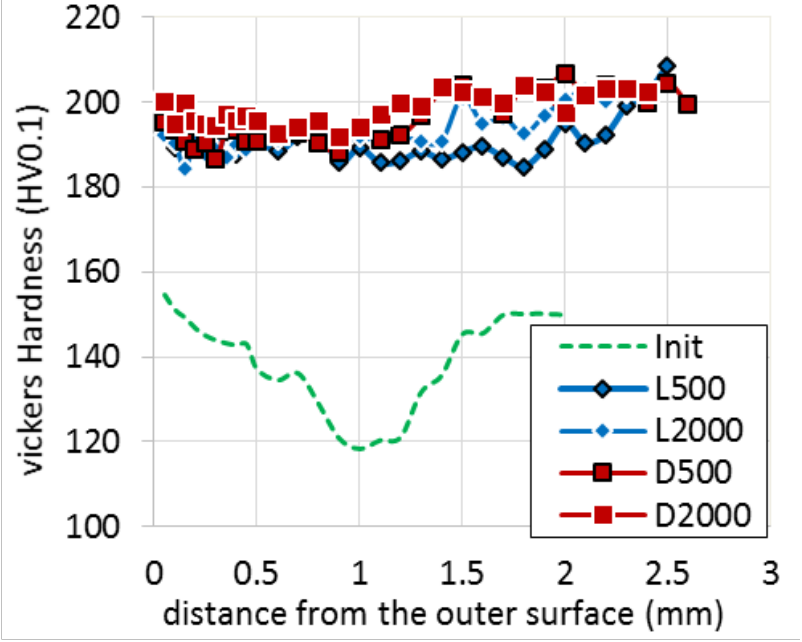

Fig. 11. Vickers hardness depth profiles of tubes for different process conditions compared to the initial state.

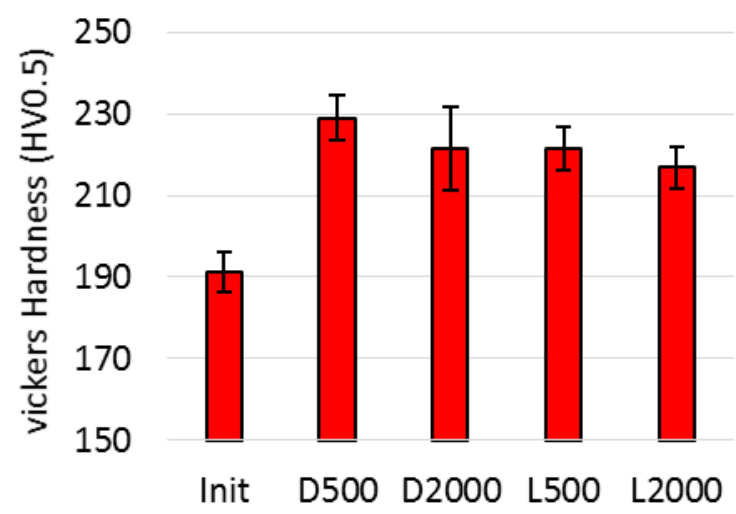

Fig. 12. Vickers hardness measured at the outer surface of tubes for different process conditions compared to the initial state.

\subsection{Residual stress}

On each sample, the residual stresses were measured at the surface along the axial direction of the tube. Figure 12 and 13 show the evolution of the surface residual stresses in axial and tangential directions along the axial position of the tube. In initial condition steady low compressive residual stresses in axial and slight tensile residual stresses in tangential directions, are present. After the rotary swaging process, all samples exhibit mainly tensile residual stresses in axial direction which are systematically shifted to lower tensile or slight compression in tangential directions. All measured residual stress distributions are highly fluctuating along the measured path, what can be attributed to the influence of the local deformation caused by incremental forming of the dies illustrated in the surface patterns (see Figure 7). The measured FWHM distributions are presented in Figure 14 and also exhibit variations for all processed samples. Compared to the initial state before rotary swaging which showed homogeneous low FWHM values, all processed samples exhibited strongly increased values due to work hardening as already observed with the hardness measurements. 


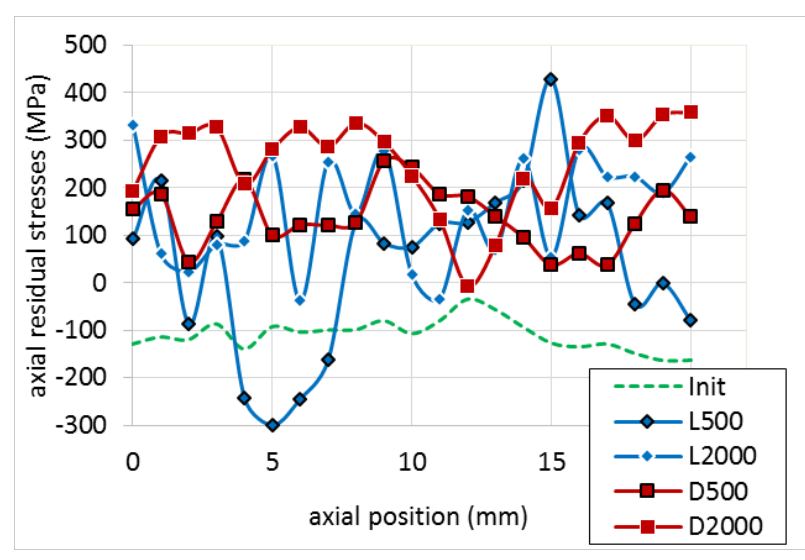

Fig. 12. Axial residual stress distribution measured along the axial direction of the tubes.

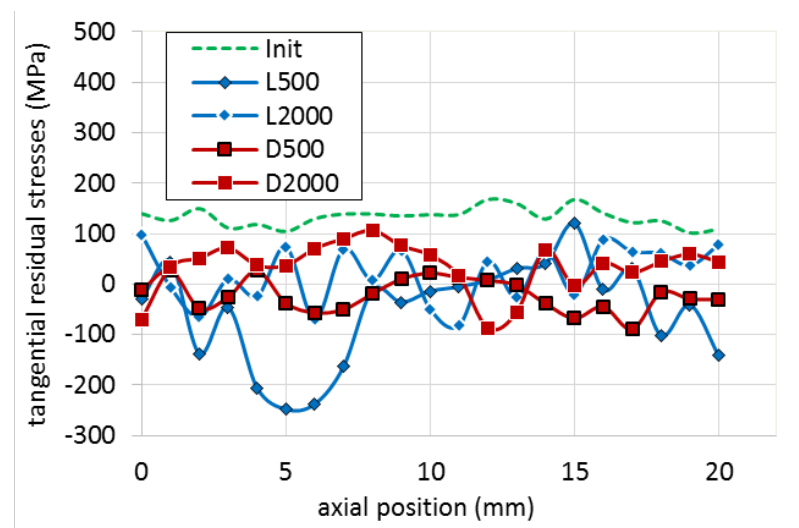

Fig. 13. Tangential residual stress distribution measured along the axial direction of the tubes.

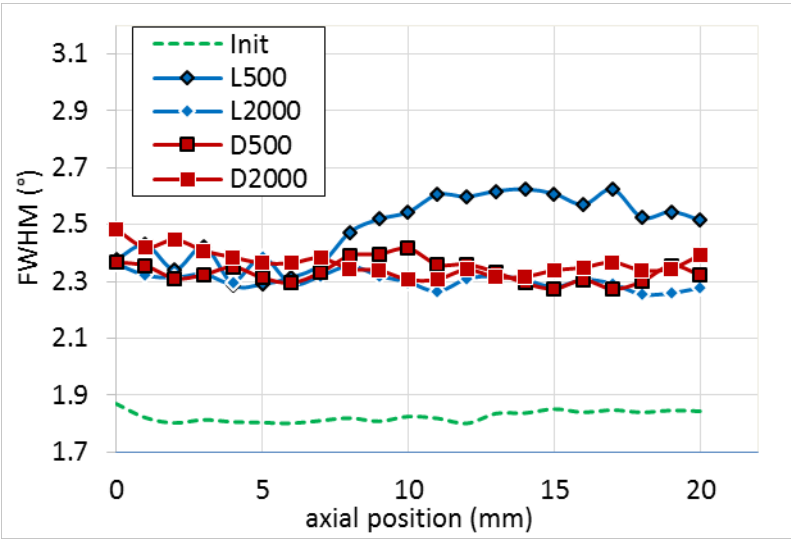

Fig. 14. FWHM distribution measured along the axial direction.

A comparison of the average values of residual stresses and FWHM measured for all samples is shown in Figure 15. Statistically, the L500 sample provided the highest FWHM values. These FWHM which reflects the local hardness correlates well with the disturbed layer under the surface found in the metallography results. The presence of a strongly deformed microstructure layer led to high FWHM by strong plastic deformation. This effect is not as pronounced for the sample L2000, while the micrographs also show a highly deformed layer. This might be explained by the fact that the surface near state is locally changing and the regions of metallographic investigations and of the XRD measurements are not exactly comparable.

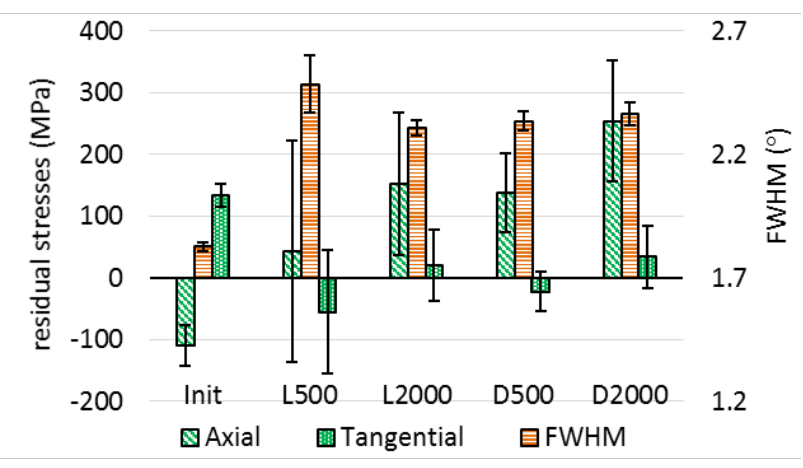

Fig. 15. Comparison of average residual stresses and FWHM at the surface.

Concerning the average residual stresses, a slight trend could be identified by the average plot in Figure 15: the high feed rate seems to induce higher tensile residual stresses than the low feed rate and the process performed without lubrication leads to the same trend. One possible explanation for this behaviour is the inhomogeneous deformation along the depth of the tube wall caused by external forces, in particular in the forging zone as observed in the simulation [17]. These stresses are result of the elastic response of the material to inhomogeneous plastic deformation.

Additionally, to the surface measurements, the axial residual stress and the FWHM were measured in the depth of previously investigated samples at a representative position in regions featuring low residual stress fluctuation. The results are shown in Figure 16 and 17. It can be observed that the initial condition was almost stress free below the surface and that the FWHM was increased in the first $50 \mu \mathrm{m}$ while in deeper regions, slightly decreasing values were present. After rotary swaging, the residual stress state was thoroughly changed in the whole evaluated depth region. Mainly tensile residual stresses were found with decreasing values in the first $50 \mu \mathrm{m}$, followed by increasing tensile stresses in further depth. In $200 \mu \mathrm{m}$ depth, the four conditions produced high tensile residual stresses that all converged to similar values. The evolution of FWHM after rotary swaging followed the same behaviour for all samples and in a depth of $50 \mu \mathrm{m}$ no pronounced differences could be observed anymore. From these results it seems that for the considered process, the rotary swaging process parameters influenced the surface near work hardening and the residual stress state in the first $200 \mu \mathrm{m}$, while in deeper depth the effect of the swaging conditions became less important. The differences at the very surface can be explained by the presence of a variously deformed layer. Additional influence of the heat generated by plastic deformation during rotary swaging is expected to play an important role in the generated residual stresses and local work hardening. The absence of extensive lubrication that flushes away the abraded particles can also influences the thermal impact of the process. 


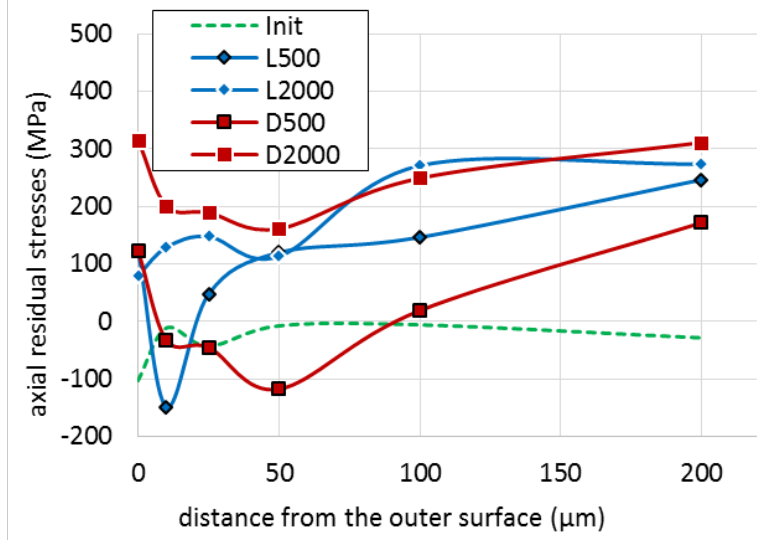

Fig. 16. Axial residual stress depth profile of the tubes.

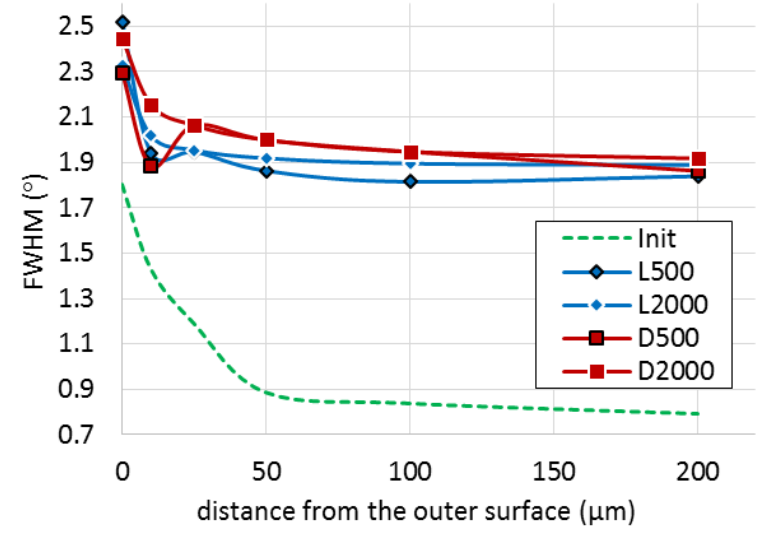

Fig. 17. FWHM depth profile of the tubes.

\section{Conclusion}

In this study, workpiece quality, material flow, the residual stress and the microstructure of steel formed with different rotary swaging parameters have been investigated. The results show that the workpiece quality is highly influenced by the feeding velocity of the process as well as the lubrication condition. Thus with higher feed and higher friction a higher roundness deviation and surface roughness was produced. Furthermore, with higher friction coefficient (dry process) more material flow occurred in axial direction which is illustrated by the experimentally measured elongation of the tubes as well as by simulation. This increased axial material flow correlates in this case of rotary swaging to a slightly higher tensile residual stress in axial direction at the investigated positions. The increase of hardness due to work hardening is pronounced at the very surface and then almost constant over the entire wall thickness. It could be shown that in the investigated parameter range, the hardness increase is almost independent on the used process parameters. The microstructure is mainly influenced near the surface by the friction condition. The obtained results can be explained by two simplified scenarios: Low effective friction lubricated rotary swaging process involves sliding of the dies on the workpiece surface. Additionally, this leads to an increased axial back flow of the material. On the other hand, dry rotary swaging process with high effective friction involves slight torsion of the workpiece with minimal peeling and leads to more axial forward flow of the material.

The investigations of the residual stress revealed that a fluctuation along the axial position results due to complexity of the interaction between the dies and the workpiece as well as the complex material flow history. The axial residual stress is mainly tensile in the first few hundreds of microns. An effect of thermo-mechanical loading during the process is expected to induce differences in the resulting residual stress distribution. The results show that the very surface is strongly influenced by the process parameters, while in higher depth the properties are comparable for all conditions. This has to be confirmed in future investigations. Moreover, for better understanding of the material modifications induced by rotary swaging process, it is important to consider the thermomechanical effects with a larger range of parameters. Additionally, the influence of further process parameters on the material modifications needs to be investigated, especially the overall deformation. Finally, the influence of workpiece rotation freedom will help to control and understand the effect of the torsion induced by the rotating dies.

\section{Acknowledgements}

The authors would like to thank the German Research Foundation (DFG Deutsche Forschungsgemeinschaft) for funding this work within the sub-project (ZO 140-23-1 and KU 1389/16-1) "Control of component properties in rotary swaging process" of the priority program SPP 2013 "The utilization of residual stresses induced by metal forming“.

\section{References}

1. E. Rauschnabel, V. Schmidt, J Mater. Process. Tech., 35, 371-383 (1992)

2. B. Kuhfuss, E. Moumi, Incremental Forming. In: Micro Metal Forming, Edition F. Vollertsen, Springer Verlag (2013)

3. Kuhfuss, B., Hollow drive shafts-a contribution towards weight and cost reduction in auto motive construction, Automotive Technology International, Sterling Publications Limited, London (1997)

4. G.D. Lahoti, T. Altan, J. Eng. In., 98, 265-71 (1976)

5. E. Moumi, S. Ishkina, B. Kuhfuss, T. Hochrainer, A. Struss, M. Hunkel, Proc. Eng., 81, 2342 - 2347 (2014)

6. Y. Wu, X. Dong, Q. Yu, Int. J. Mech. Sci., 93, 102110 (2015).

7. Y. Liu, M. Herrmann, C. Schenck, B. Kuhfuss, AIP Conf. Proc., 1896, 080013 (2017)

8. R. Paukert, Stofffluss beim Radialumformen - Teil 1, DRAHT, 35, 108-111 (1984)

9. B. Scholtes, Eigenspannungen in mechanisch randschichtverformten Werkstoffzuständen: 
Ursachen, Ermittlung und Bewertung, Oberursel, DGM-Informationsges (1991)

10. A. Ameli, M. R. Movahhedy, Int. J. Adv. Manuf Tech., 33, 7-17 (2017)

11. M. Herrmann, C. Schenck, B. Kuhfuss, DMOAJ FMT (to be published)

12. J. Epp, , G. Huebschen, I. Altpeter, R. Tschuncky, H.G., Herrmann, X-ray diffraction techniques for material characterization: Materials Characterization Using Nondestructive Evaluation (NDE) Methods, (Eds), Woodhead publishing, 81124 (2016)

13. J. Epp, H. Surm, T. Hirsch, F. Hoffmann, J. Mater. Proc. Tech., 211, 637-643 (2011)

14. M. Herrmann, C. Schenck, B. Kuhfuss, Key Eng. Mat., 651-653, 1042-1047 (2015)

15. H. Hetzner, Systematische Entwicklung amorpher Kohlenstoffschichten unter Berücksichtigung der Anforderungen der Blechmassivumformung, dissert., University of Erlangen (2014)

16. J. Dong, J. Epp, A. Rocha, R. Nunes, H.-W. Zoch, Met. Mat. Trans. A, 47A, 877-888 (2016)

17. Z. Wang, B. Gong, Residual Stress in the Forming of Materials, ASM Handbook of Residual Stress and Deformation of Steel, ASM International, USA, 141149 (2002). 